\title{
QUEEN'S
UNIVERSITY
BELFAST
}

\section{Evaluation of a dustbathing substrate and straw bales as environmental enrichments in commercial broiler housing}

Baxter, M., Bailie, C. L., \& O'Connell, N. E. (2018). Evaluation of a dustbathing substrate and straw bales as environmental enrichments in commercial broiler housing. Applied Animal Behaviour Science, 200, 78-85. https://doi.org/10.1016/j.applanim.2017.11.010

Published in:

Applied Animal Behaviour Science

Document Version:

Peer reviewed version

Queen's University Belfast - Research Portal:

Link to publication record in Queen's University Belfast Research Portal

Publisher rights

(C) 2017 Elsevier B.V. All rights reserved

This manuscript version is made available under the CC-BY-NC-ND 4.0 license http://creativecommons.org/licenses/by-nc-nd/4.0/,which permits distribution and reproduction for noncommercial purposes, provided the author and source are cited.

\section{General rights}

Copyright for the publications made accessible via the Queen's University Belfast Research Portal is retained by the author(s) and / or other copyright owners and it is a condition of accessing these publications that users recognise and abide by the legal requirements associated with these rights.

Take down policy

The Research Portal is Queen's institutional repository that provides access to Queen's research output. Every effort has been made to ensure that content in the Research Portal does not infringe any person's rights, or applicable UK laws. If you discover content in the Research Portal that you believe breaches copyright or violates any law, please contact openaccess@qub.ac.uk. 


\section{Evaluation of a dustbathing substrate and straw bales as environmental enrichments in commercial broiler housing \\ Mary Baxter*, Carley L Bailie, Niamh E. O'Connell \\ Institute for Global Food Security, Queens University Belfast, 18-30 Malone Road, Belfast, Northern Ireland, BT9 5BN. mbaxter1004@qub.ac.uk.}

*Corresponding author: M Baxter, mbaxter1004@qub.ac.uk

\section{Abstract}

The use of straw bales as an environmental enrichment is common for broiler chickens in enriched housing systems, however relatively little information exists about their effectiveness in improving welfare. There has also been no widespread introduction of a dustbathing material for broilers. The main aim of this trial was to evaluate the use of a dustbathing substrate (in the form of oat hulls), both as an alternative to straw bales and as a supplementary enrichment. Over four replicates, four commercial houses, each containing approximately 22,000 broilers, were assigned to one of four treatments over the 6-week production cycle: (1) straw bales (B; one per $\left.155 \mathrm{~m}^{2}\right),(2)$ oat hulls as a dustbathing substrate $\left(\mathrm{OH}\right.$; provided in $1 \mathrm{~m}$ diameter steel rings, one per $\left.155 \mathrm{~m}^{2}\right),(3)$ both oat hulls and straw bales $(\mathrm{OH}+\mathrm{B})$, and (4) a control treatment with no environmental enrichment $(\mathrm{C})$. Observations of broiler behaviour and leg health were taken weekly, and performance data was collected for each cycle. Broilers housed in the $\mathrm{OH}$ and $\mathrm{OH}+\mathrm{B}$ treatments had better gait scores in week 6 than those housed in the $C$ treatment $(P<0.05)$, which suggests that the provision of oat hulls improved bird leg health. However, there was no associated increase in activity levels in unenriched areas of the houses. Conversely, more locomotion $(P<0.001)$, less sitting inactive $(P<0.001)$ and less sitting pecking $(P<0.001)$ were observed in the $\mathrm{C}$ treatment than in unenriched areas of $\mathrm{B}, \mathrm{OH}$ and $\mathrm{OH}+\mathrm{B}$ treatments. More birds were recorded around the bales compared to the oat hulls $(P<0.001)$, however birds performed significantly more foraging $(P=0.019)$ and dustbathing $(P=0.045)$ in oat hulls than around straw bales. Although oat hulls appear to be more suitable for stimulating active 
behaviours than straw bales, the high level of resting recorded around the bales suggests they may have a positive function as protective cover. The presence of an additional type of enrichment in the house did not affect the number of birds, or the type of behaviours performed in close proximity to either straw bales or oat hulls $(P>0.05)$. Treatment did not have a significant effect on pododermatitis levels or slaughter weight, on mortality rates, or on litter quality or atmospheric ammonia levels $(P>0.05)$. Overall, our results suggest that the oat hulls substrate was a successful enrichment in terms of promoting dustbathing and foraging, and improving bird leg health. The straw bales also appeared attractive to the birds, however, which suggests that a dustbathing substrate should be a supplementary enrichment.

Keywords: broiler chicken; environmental enrichment; dustbathing; welfare; leg health Highlights:

- Broilers had better gait scores when provided with a dustbathing substrate

- Oat hulls appear to be a successful commercial dustbathing substrate

- Straw bales were also attractive to birds but did not promote as much activity

- A dustbathing substrate is suggested as a supplementary enrichment to straw bales 


\section{Introduction}

Broiler chickens are typically housed in indoor systems, in groups of several thousand, and bedded on deep litter. With the exception of feeder and drinker lines, the houses do not usually contain additional furniture or stimulation. Providing domestic fowl with more complex environments has improved stereotypical pecking behaviours (Nørgaard-Nielsen et al., 1993), fear reactions (Jones and Waddington, 1992; Reed et al., 1993), learning (Krause et al., 2006), activity levels (Kells et al., 2001) and leg condition (Mench et al., 2001; Bizeray et al., 2002a). Chickens will readily enter areas containing novel items (Newberry, 1999) and will spend more time in preferred foraging and dustbathing substrates when provided (Shields et al., 2004). Crucially, introducing barriers (Bizeray et al., 2002a) and straw bales (Kells et al., 2001) has been shown to increase activity levels in broilers. Modern broilers will spend up to $86 \%$ of their time sitting down (Weeks et al., 2000), with this inactivity linked to a high prevalence of skeletal conditions and leg disorders that get worse with age (Vestergaard and Sanotra, 1999; Danbury et al., 2000; Knowles et al., 2008). Providing broilers with a more complex environment is therefore likely to improve bird welfare, both by improving leg health and by providing a stimulating environment to promote natural behaviours (Newberry, 1995).

Although there is no current legal requirement for broilers to be provided with environmental enrichment, those housed under conditions dictated by welfare assurance schemes are often supplied with some variation of natural light, perches and/or straw bales (e.g. CIWF, 2017). Foraging and dustbathing are highly motivated behaviours and preventing birds from performing them leads to observable frustration (Lindberg and Nicol, 1997; Vestergaard et al., 1997; Fraser and Duncan, 1998). Providing a foraging substrate, in the form of straw bales, should therefore have a positive effect on welfare. However, there is limited research on the use of bales provided at a commercial level. Kells et al. (2001) showed that providing broilers with straw bales increased their overall activity levels, however their trial used a higher number of bales than are supplied commercially. More recent research that involved 
lower straw bale densities, chosen to more closely reflect current industry practice, did not yield similar findings (Bailie et al., 2013; Bailie and O'Connell, 2014). Similarly, although smaller scale research has been conducted on the preference of broilers for different dustbathing substrates (e.g. Shields et al., 2004), there has been no widespread introduction of dustbathing enrichments. Dustbathing consists of birds kicking a loose friable substrate through their feathers and is a highly-motivated behaviour (van Liere et al., 1991; Vestergaard et al., 1997; Vestergaard and Sanotra, 1999). Broilers with tibial dyschondroplasia will dustbathe significantly less than their healthy counterparts, which may be due to dustbathing requiring rotation and movement of the legs (Vestergaard and Sanotra, 1999). Broilers have shown a preference for peat and sand as dustbathing materials (Shields et al., 2004; de Jong et al., 2007), however these substrates are expensive, unsustainable and may interfere with the litter removal process. A practical alternative has been suggested in the form of ground oat hulls, which are a by-product of oat milling. Broilers appear to identify oat hulls as a dustbathing substrate and perform comparable dustbathing bouts in oat hulls and peat (Baxter and O'Connell, 2016), however their effectiveness as a form of environmental enrichment has not yet been evaluated under commercial conditions.

This experiment was designed to evaluate different environmental enrichment conditions for commercial broiler chickens. This included assessing the effectiveness of straw bales (when provided at a level that reflects practice on some commercial farms), a comparable quantity of oat hulls, both straw bales and oat hulls, and a control treatment with no straw bales or oat hulls. There was a particular interest in understanding whether oat hull dustbaths should be used as an alternative or supplementary form of environmental enrichment to straw bales. The effects of different enrichment treatments on general behaviour of the birds (both in close proximity to, and away from the enrichments), on measures of health and performance, and on environmental measures within the house were determined. 


\section{Methods}

This trial was approved by the School of Biological Sciences (Queen's University Belfast) Research Ethics Committee (reference number QUB-BE-AREC-17-001).

\subsection{Subjects and Housing}

A total of 355400 Ross 308 broiler chickens (Aviagen Ltd, UK) were used in this study and were reared from a day old on a commercial farm in Northern Ireland. The trial was repeated for four production cycles between July and December 2015. Four metal framed, windowed broiler houses were used on this farm. Two houses had a floor space of $1398 \mathrm{~m}^{2}$ and two had a floor space of $1395 \mathrm{~m}^{2}$ due to different positioning of outbuildings. Approximately 22 000 birds were placed in each house 'as hatched', which gave an approximate 50:50 mix of males and females. This gave an initial stocking density of 16 birds $/ \mathrm{m}^{2}$. A proportion of the birds were removed for thinning at approximately day 30 , and the remaining birds were cleared between days 37 and 42 . Temperature and humidity were controlled automatically to maintain levels within the commercial standard. Natural light was provided through 43 windows along the long sides of the house (measuring $220 \mathrm{~cm}$ wide $\times 60 \mathrm{~cm} \mathrm{high}$, at a height of $1.5 \mathrm{~m}$ ), artificial strip lighting was also provided. The lighting regime used followed EU regulations: time in darkness increased by 1 hour per day, from 1 hour at a day old to 6 hours on day 7 , and then decreased on day 29 by 1 hour per day to 1 hour of darkness which was maintained from day 33 to slaughter. Fresh woodshavings were used to bed the house at the beginning of each cycle, before the birds were placed, with additional shavings then distributed at the farmer's discretion across the cycle.

\subsection{Treatments and Experimental Design}

In order to investigate the effectiveness of different enriched conditions, the four commercial houses were assigned to one of four treatments: 1) Bales (B), 2) Oat Hulls $(\mathrm{OH}), 3$ ) Oat Hulls and Bales $(\mathrm{OH}+\mathrm{B}), 4)$ Control $(\mathrm{C})$. This trial was repeated over four cycles, with each house assigned to each treatment once. In treatments containing straw bales, nine plastic- 
wrapped bales of chopped straw (approximately $0.8 \mathrm{~m}$ long $\times 0.4 \mathrm{~m}$ wide $\times 0.4 \mathrm{~m}$ high) were placed evenly around the house on Day 10, which matched normal practice on this farm. Five bales were placed down the central line of the house and four around the edge of the house. Oval cuts were made in the plastic at the sides of the bales to allow access to the straw (Figure 1), and once the top of the bale had collapsed through use, it was replaced in the same location. Existing bales were dismantled (and plastic removed) just prior to thinning, and were replaced with nine new bales after thinning. In total, two bales per 1000 birds ( 46 bales; 1 per $155 \mathrm{~m}^{2}$ ) were used across a 6-week cycle in a particular house.

Oat hulls were the ground outer hull of oats, produced locally as a by-product of oat milling, with a colour and consistency similar to fine sawdust. Oat hulls have previously been used in nutritional trials with broilers chickens (e.g. Hetland and Svihus, 2001). The oat hulls were provided in a manner which attempted to emulate the level of provision of straw bales. Nine stainless steel rings ( 1 per $155 \mathrm{~m}^{2} ; 1.1 \mathrm{~m}$ diameter, $7.6 \mathrm{~cm}$ deep) were placed in corresponding sections of the house to the B treatment. The area of the rings $\left(\sim 0.95 \mathrm{~m}^{2}\right)$ was chosen such that it was equal to the area of two sides and two ends of a straw bale. The rings were placed in the house on day 10 and filled with approximately $9 \mathrm{~kg}$ of oat hulls. Oat hull rings were then topped up to the original level throughout the cycle when more than half of the substrate in them had gone. Oat hulls were always topped up to their original condition on the morning of observations to ensure they were in a standardised condition. In the $\mathrm{OH}+\mathrm{B}$ treatment both types of enrichment were placed in the corresponding sections of the house that contained enrichments in the other treatments; there was always a feeder or drinker line separating the two enrichments which were placed approximately $1.5 \mathrm{~m}$ apart. No environmental enrichments were provided in the $\mathrm{C}$ treatment.

\subsection{Data Collection}

The farm was visited twice a week in weeks 3-6 of each cycle and all measurements were taken by the same observer. 
Video recordings of broiler behaviour were performed on the first day of data collection each week using five Toshiba Camileo X-Sports cameras placed on $1.5 \mathrm{~m}$ high wooden tripods. Using feeder and drinker lines, the house was virtually sectioned into 66 approximately equal sections. These sections were classified as "enriched" (sections that contained an enrichment), "unenriched", "edge" (sections that had a side made up of the house wall) and "central". In each house, a total of four hours of video footage was taken between 9:00 h and 15:00 h per week. This consisted of half-hour recordings taken in eight different locations. In the $\mathrm{B}$ and $\mathrm{OH}$ treatments, four half-hour recordings were taken of four randomly chosen enrichments, two central and two edge. The remaining four half-hour videos were taken of unenriched areas of the house, two in edge locations and two in central locations. In the $\mathrm{C}$ treatment, sections chosen corresponded to "enriched" and "unenriched" sections of the other treatments. In the $\mathrm{B}+\mathrm{OH}$ treatment, the same approach was adopted as above except that a second camera was used to allow for both types of enrichment to be recorded in the enriched sections of the house. The cameras were set up in all four houses and were switched on one after another by the same observer; the order that the cameras were switched on was therefore randomised to control for the slight difference in video starting times.

To analyse footage, for each half hour video ( $\mathrm{n}$ total $=512$ ) scan sampling was used to count the number of birds and to categorise the behaviour of each bird according to an ethogram (Table 1). The \% of birds engaged in different behaviours was then calculated. Two scans were performed per recording, one at 10 minutes and one at 20 minutes. The "scan areas" were balanced as far as possible considering the different enrichments filmed. In footage containing a ring, all birds inside the rings were counted and categorised. In bale videos, a side and end of the bale were outlined and transposed onto the floor area around the bale which gave an area equivalent to half the area of a ring and equated to approximately $0.4 \mathrm{~m}$ in front of and to the side of the bale. As only one side of the bale could be filmed, this count was doubled for analysis, as in Kells et al. (2001). In footage of empty (unenriched) floor 
area, an outline of a ring was used in the centre of frame and birds with more than half their body across this line were counted and categorised.

On the second day of data collection each week, environmental measures and gait scores were recorded. Litter samples were taken from eight random locations around the house, four from central sections and four from edge sections. Samples were collected in plastic bags, thoroughly mixed and stored in a cool box for transport. Following drying for 24 hours at $70^{\circ} \mathrm{C}$, the dry matter percentage of the litter was calculated (McLean et al., 2002; Bailie et al., 2013). To give an indication of ammonia within each house, pHydrion ${ }^{\mathrm{TM}}$ (Dewey et al., 2000) paper tests were used in four locations (two front and two back) in each house. Each test strip was moistened with distilled water and held at bird head height for 15 seconds, after which the colour of the paper gave an indication that ammonia was either $0,5,10,20$, 50 or $100 \mathrm{ppm}$. These four scores were averaged to give an average ammonia score per house, per week. Gait scoring was performed using the Modified Gait Scoring Method (Garner et al., 2002). Each week, two birds were gait scored from 20 random sections of each house (total of 2560 birds). Within the sections, the two birds were randomly chosen using a numbered grid on a perspex sheet (Kells et al., 2001; Bailie et al., 2013). The sheet was held at arm's length and the birds closest to the randomly generated co-ordinates on the grid were given a gait score of 0-5 (Garner et al., 2002).

Mortality (which is the number of birds removed dead from the house and does not include culled birds), downgrades (which consists of birds deemed imperfect at the slaughterhouse, for example due to contamination, damage at defeathering or being undersized), the number of culls performed and slaughter weight of the birds were taken from company records. Levels of pododermatitis were recorded at slaughter in one hundred birds per house at thinning and one hundred birds per house at final clearing. Pododermatitis was recorded by slaughterhouse staff on a scale of $0-2$, where ' 0 ' represents either no pododermatitis or very superficial lesions, ' 1 ' represents mild pododermatitis on either foot with discolouration of the 
footpad and superficial lesions, and ' 2 ' is recorded when there is severe pododermatitis on either foot with ulcers, signs of haemorrhage and/or swollen footpads.

\section{Statistical analysis}

All data were analysed using IBM SPSS Statistics (Version 23). Data normality was assessed through inspection of residual histograms, Q-Q plots and Shapiro-Wilk tests. Where equal variance could not be assumed, adjusted degrees of freedom are presented. Post-hoc tests, where applied, were chosen based on whether the assumptions of equal variance and equal sample size were met.

Scan data representing the number of birds close to each type of enrichment (i.e. in oat hull rings or close to straw bales), and the percentage of birds engaged in different behaviours while close to each type of enrichment and while in unenriched areas, were averaged withintreatment each week. Data on the \% of birds engaged in different behaviours in unenriched areas could not be sufficiently transformed for parametric analysis. Therefore, the main effects of "treatment" $(\mathrm{OH}, \mathrm{B}, \mathrm{OH}+\mathrm{B}, \mathrm{C})$ and of "age" were analysed using Kruskall-Wallis tests. The main effect of "cycle" was also tested and no significant effects were found for any behaviour $(P>0.05)$. Dustbathing and Other were infrequently recorded and were excluded from analysis.

To determine whether the presence of an alternative enrichment had an effect on the way individual enrichments were used, oat hulls and bales in the single treatments $(\mathrm{OH}, \mathrm{B})$ were compared with their counterparts in the $\mathrm{OH}_{+} \mathrm{B}$ treatment. The total number of birds and occurrence of each behaviour (\%) in the rings of oat hulls in the $\mathrm{OH}$ compared to the $\mathrm{OH}+\mathrm{B}$, and around the bales in the $\mathrm{B}$ compared to $\mathrm{OH}+\mathrm{B}$ treatment were analysed. Independent samples t-tests were used to compare total numbers of birds. GLMM was used to compare the percentage of birds observed in each behaviour category between the single and combined treatment, with "treatment" and "age" as fixed factors and "cycle" as a random factor; a log10 transformation and +1 constant was applied to improve normality where necessary. 
To compare the use of oat hulls and straw bales in general, data from enrichments in single treatments $(\mathrm{OH}$ or $\mathrm{B})$ were combined with their counterpart in the combined treatment $(\mathrm{OH}+\mathrm{B})$ to give combined data for oat hulls (from $\mathrm{OH}$ and $\mathrm{OH}+\mathrm{B}$ ) and for bales (from $\mathrm{B}$ and $\mathrm{OH}+\mathrm{B})$. An independent samples t-test was used to compare the combined total number of birds interacting with the straw bales and oat hulls. The difference in behaviours (\%) performed in oat hulls and bales was compared using GLMM. Each behaviour was modelled separately, with "enrichment type (OH or B)" and "age" as fixed factors and "cycle" as a random factor. Significant interactions were further investigated using simple effects analysis. Where there was a significant main effect, post-hoc tests were performed using a Tukey test where equal variance could be assumed and a Games-Howell test when this assumption was violated. Preening was infrequently recorded, and therefore "standing preening" and "sitting preening" were grouped to facilitate analysis.

Performance data and levels of pododermatitis were recorded once at the end of each cycle, and, as such, the GLMM for analysis consisted of "treatment" as a fixed factor and "cycle" as a random factor. Gait score data were ordinal and the effect of treatment was analysed using Kruskall-Wallis tests within weeks, with follow-up stepwise stepdown multiple comparison (based on Campbell and Skillings, 1985). Ammonia measures were analysed using a oneway ANOVA to compare average ammonia between treatments $(\mathrm{OH}, \mathrm{B}, \mathrm{OH}+\mathrm{B}, \mathrm{C})$. Litter moisture data were analysed using GLMM with "treatment" and "age" as fixed factors and "cycle" as a random factor.

\section{Results}

\subsection{Behaviour in unenriched areas of all treatments}

Treatment had a significant effect on the majority of the behaviours observed (median values presented in Table 2). Birds in the control treatment performed less sitting inactive $(H(3)=$ 36.8, $\mathrm{n}=64, P<0.001)$ and sitting pecking $(\mathrm{H}(3)=35.5, \mathrm{n}=64, P<0.001)$, and more locomotor behaviour $(\mathrm{H}(3)=36.6, \mathrm{n}=64, P<0.001)$ compared to birds in the three enriched treatments. Higher levels of preening while birds were sitting down was observed in the 
$\mathrm{OH}+\mathrm{B}$ compared to the control treatment $(\mathrm{H}(3)=7.9, \mathrm{n}=64, P=0.048)$, and significantly more preening while standing was performed in the control compared to the enriched treatments $(\mathrm{H}(3)=24.3, \mathrm{n}=64, P<0.001)$. There were no differences in the levels of foraging or resting observed between treatments $(P>0.05)$. Foraging was the only behaviour to be significantly affected by age $(\mathrm{H}(3)=22.78, \mathrm{n}=64, P<0.001)$; the median percentage of birds foraging was 2.5 in week $3,1.0$ in week 4 , and 0 in weeks 5 and 6 . Pairwise comparisons showed that foraging was significantly higher in week 3 compared to week $5(P<0.001)$ and week $6(P=0.001)$.

\subsection{Effect of the presence of an alternative enrichment}

There was no significant difference in the mean number of birds recorded in the rings in the $\mathrm{OH}(\mathrm{M}=14.49, \mathrm{SE}=1.44)$ compared to the $\mathrm{OH}+\mathrm{B}(\mathrm{M}=15.05, \mathrm{SE}=1.68)$ treatment $(\mathrm{t}(30)=$ $-0.25, P=0.80)$, or the mean number of birds in close proximity to the bales in the $\mathrm{B}(\mathrm{M}=$ 28.69, $\mathrm{SE}=2.91)$ compared to the $\mathrm{OH}+\mathrm{B}(\mathrm{M}=30.91, \mathrm{SE}=3.15)$ treatment $(\mathrm{t}(30)=-0.52, P$ $=0.61$ ). There were also no differences in the level of any behaviours in the single compared to the combined treatments (Table 3) and no significant interactions.

\subsection{Differences in the use of oat hulls and straw bales}

There was a significant interaction between enrichment type and age for dustbathing $\left(F_{3.9}=\right.$ 8.004, $P=0.007)$ and foraging $\left(F_{3,9}=12.08, P=0.002\right)$ (Table 4$)$, which indicates that birds used the two enrichment types differently as they aged (Figure 2). Specifically, the amount of birds foraging and dustbathing changed over time in the oat hulls but not around the bales. The mean percent of birds in the oat hulls that were dustbathing increased as birds aged (week $3, M=5.04 \%$, SE = 1.31; week 4, $M=12.27 \%$, SE $=3.08$; week $5, M=17.61 \%$, SE = 5.29 ; week $6, M=21.22 \%, S E=2.98)$, but very few incidences of dustbathing were recorded around the bales throughout the production cycle (week $3, M=0 \%$; week $4, M=$ $1.21 \%, \mathrm{SE}=1.20$; week $5, \mathrm{M}=0.12 \%, \mathrm{SE}=1.16$; week $6, \mathrm{M}=0 \%$ ). More foraging was consistently seen in the oat hulls compared to around the bales, however levels of foraging 
decreased in the oat hulls over time (week $3, M=48.42 \%$, SE $=5.99$; week $4, M=24.62 \%$, $\mathrm{SE}=3.44$; week $5, \mathrm{M}=23.02 \%, \mathrm{SE}=2.77$; week $6, \mathrm{M}=19.01 \%, \mathrm{SE}=3.38)$ and remained similar around the bales (week $3, M=7.00 \%, S E=1.26$; week $4, M=6.18 \%, S E=2.10$; week $5, \mathrm{M}=6.37 \%$, SE = 1.44; week $6,5.84 \%$, SE = 2.08).

In addition to the interactions described above, significant main treatment effects were also found (Table 4). For example, a higher level of sitting pecking was observed in the oat hulls, while birds around the straw bales showed more inactivity, preening and "other" behaviours. There was also a main effect of age on preening, however no enrichment by age interaction was seen and levels generally varied between weeks (week $3, M=5.22 \%$, SE $=0.78$; week $4, M=6.54 \%, S E=0.80$; week $5, M=3.48 \%, S E=0.62$; week $6, M=5.78 \%, S E=1.72$ ).

Overall, significantly more birds were recorded around the bales $(M=29.80, S E=2.12)$ than inside the oat hulls $(\mathrm{M}=14.77, \mathrm{SE}=1.09 ; \mathrm{t}(46.3)=-6.31, P<0.001)$.

\subsection{Health and performance}

Treatment did not have a significant effect on average bird slaughter weight, culls, downgrades or levels of pododermatitis $(P>0.05)$ (Table 2). However, there was a significant effect of treatment on \% mortality $(P=0.003)$, with post-hoc tests showing a trend for higher levels of mortality in the oat hulls compared to the oat hulls and bales $(P=0.070)$, however there was no significant difference between any of the enriched treatments and the control $(\mathrm{OH} 1.55 \%, \mathrm{SE}=0.09 ; \mathrm{B} 1.08 \%, \mathrm{SE}=0.12 ; \mathrm{OH}+\mathrm{B} 1.05 \%, \mathrm{SE}=0.15 ; \mathrm{C} 1.32 \%, \mathrm{SE}$ $=0.14 ; P>0.40)$. The lack of clear differences between individual treatments for mortality are likely to be due to the impact of cycle within the model as there was an unexplained high level of mortality in one cycle.

\subsection{Leg health}

The distribution of gait scores between treatments for each week are presented in Table 5. More birds were classified with worse gait scores over time, in all treatments. Treatment had no effect on gait score in weeks 3,4 and $5(P>0.05)$, however there was a significant effect 
of treatment in the final week $(\mathrm{H}(3)=8.19, P=0.042)$. In week 6 , birds provided with oat hulls (mean rank 305.60) or oat hulls and bales (mean rank 304.44) had lower gait scores than birds in the control treatment (mean rank 350.72; $P<0.05$ ). Birds in the bales treatment (mean rank 321.24) had similar gait scores to the oat hulls, oat hulls + bales $(P=0.57)$ and control treatments $(P=0.79)$.

\subsection{Environmental Measures}

There was no significant effect of treatment on litter moisture or ammonia levels $(P>0.05)$ (Table 2). Age did have an effect on litter moisture $\left(F_{3,64}=5.20, P=0.03\right)$, with a temporary increase in overall litter moisture in week 4 of the cycle. However, no overall increase was seen over time, with no significance difference between weeks 3, 5 and 6 .

\section{Discussion}

In this trial, providing broilers with oat hulls, both in combination with straw bales and as a stand-alone dustbathing enrichment, led to an improvement in gait score in the final week of the production cycle. Birds in close proximity to the oat hulls and straw bales show a marked difference in the way they used the enrichments, with more foraging and dustbathing performed in oat hulls, and more sitting inactive observed around straw bales. When provided together, there was no effect on the level of use of adjacent oat hulls and straw bales compared to when they were provided in separate houses. A significant effect of treatment on the behaviour of broilers away from the enrichments was found, although our findings contradict previous research that showed an increase in activity (Kells et al., 2001). Conversely, we report a decrease in locomotion and an increase in sitting behaviours in all enriched treatments compared to the unenriched control.

Broilers with access to oat hulls, in the $\mathrm{OH}$ and $\mathrm{OH}+\mathrm{B}$ treatments, recorded better gait scores compared to those housed in the $C$ treatment with no enrichment. Birds housed with only straw bales fell somewhere in the middle, with slightly lower gait scores than those in the control treatment $(P=0.79)$ and slightly higher scores to those recorded in the $\mathrm{OH}$ and 
$\mathrm{OH}+\mathrm{B}$ treatments $(P=0.57)$. Broilers are particularly susceptible to skeletal disorders that impair mobility and can spend up to $76-86 \%$ of their time sitting down by slaughter weight (Weeks et al., 2000). This inactivity can, in turn, lead to a worsening of leg health and additional damage such as contact dermatitis (Bessei, 2006). These disorders are assumed to be painful and birds with gait scores $>2$ are considered to have poor welfare (Vestergaard and Sanotra, 1999; Danbury et al., 2000). When young broilers are forced to exercise they show a reduction in leg abnormalities by slaughter age, supporting the link between inactivity and poor leg health (Thorp and Duff, 1988; Bessei, 2006). Promoting activity in broilers has been attempted practically by increasing the distance between feeders and drinkers, which led to increased locomotion and improved leg condition (Reiter and Bessei, 1996). Increasing broilers' environmental complexity with barriers, perches and straw bales has been shown to increase activity (Kells et al., 2001; Bizeray et al., 2002a). Providing oat hulls may have acted in a similar manner, by providing birds the opportunity to exercise and improve the incidence of poor leg health. Dustbathing is an active behaviour that begins with birds scratching at the ground before squatting on the substrate with their feathers erect. The birds then use leg kicks, scratches and vertical wing shakes (an upward shuffling motion) to move dust into their feathers (van Lierre et al., 1991). The leg and body movements involved may have helped to develop bone and muscle conformation, leading to an improvement in leg health by slaughter weight (Sandusky and Heath, 1988; Rutten et al., 2002; Bessei, 2006).

Contrary to our expectations, there were higher levels of locomotion and less sitting inactive in the control treatment compared to unenriched areas of $\mathrm{OH}, \mathrm{B}, \mathrm{OH}+\mathrm{B}$ treatments. Considering the improvement in gait score in enriched treatments, it seems unlikely that the reduction in activity was as a result of poorer leg health. It is possible that the presence of the straw bales and/or oat hulls in the enriched treatments led to a reduction in the amount of time birds spent exploring to find suitable resources for foraging and dustbathing (Nicol and Guildford, 1991). However, broilers' time budgets are fairly inflexible in different 
enrichment conditions (Shields et al., 2005), and it may be that providing enrichments that promote exploratory and dustbathing behaviour creates areas of activity in enriched treatments, and that unenriched areas are primarily used for rest. It is therefore difficult to establish whether overall levels of activity by broiler chickens were affected by treatment in the current study. Previous trials have provided broilers with varying numbers of straw bales and reported either an increase in overall activity (Kells et al., 2001) or no effect on any behaviours (Bailie et al., 2013; Bailie and O'Connell, 2014). It is likely that the discrepancy in bale density can account for the difference in results. Kells et al. (2001) reported an increase in locomotion and standing, and a decrease in sitting and resting in houses with bales compared to barren housing. Their enriched houses contained a high density of straw bales (118 in one house and 81 in another; 1 bale per $\left.17 \mathrm{~m}^{2}\right)$, compared to the current trial ( 9 bales at any one time and 46 across the cycle, equating to 2 / 1000 birds; 1 per $155 \mathrm{~m}^{2}$ ). There has been little research on different levels of bale provision, however Bailie and O'Connell (2014) found no improvement in bird welfare when broilers were housed with 1 bale per $29 \mathrm{~m}^{2}$ ( 2 bales per 1000 birds at all times) compared to a lower 1 bale per $44 \mathrm{~m}^{2}$ (1.3 bales per 1000 birds at all times). Currently protocols for enriched housing in the UK (usually $1.5-2$ bales per 1000 birds) were largely developed within the limitations of what could practically be implemented on farms at the time, however further research on the optimal level of bale provision would be useful.

The behaviour of broilers in close proximity to the oat hulls or straw bales was considerably different. Birds performed more dustbathing, foraging and sitting pecking in oat hulls compared to when they were around straw bales. Oat hulls are a loose, friable substrate and possess qualities similar to peat and sand, for which broilers show a preference for foraging and dustbathing (e.g. Petherick and Duncan, 1989; Shields et al., 2004). Although all straw bales provided during the trial were dismantled, which means birds did peck and scratch the straw throughout the cycle, levels of foraging behaviour observed around the bales were low. Foraging in broilers is a relatively short behaviour, with average foraging bouts lasting 
around 3 minutes (Bizeray et al., 2002b), which may have been missed by scan sampling. However, the high levels of sitting inactive observed suggests the bales may serve another positive function by providing cover and perceived protection for broilers. Increased levels of resting and preening are observed in birds provided with cover panels, probably because they would be particularly vulnerable to predation while their eyes are closed (Newberry and Shackleton, 1997; Cornetto and Estevez, 2001b). Homogeneity of distribution of birds is also improved with the presence of cover, as birds have a tendency to group near pen walls (Cornetto and Estevez, 2001a). There was also a difference in the way the two enrichments were used over time. While foraging and dustbathing remained low around straw bales, in oat hulls there was a reduction in foraging over time and an increase in dustbathing between weeks 3 and 6. Consistent with previous research (e.g. Dawson \& Siegel, 1967), there was also a reduction in foraging in the unenriched areas of the house. Foraging is also an example of contrafreeloading, whereby an animal with easy access to food will choose to work for food (Osbourne, 1977). Broilers have constant access to food and are less likely to perform contrafreeloading behaviours compared to laying hens and their Red Jungle Fowl ancestors (Lindqvist et al., 2006), and this may especially become the case when the activity requires more energy in older and heavier birds. Dustbathing has a different motivational basis and we report an increase in the level of dustbathing between weeks 3 and 6 , which corresponds with some previous studies (Weeks et al., 1994; Bokkers and Koene, 2003). These results suggest that a dustbathing substrate may be a more suitable enrichment for birds to engage with for the entirety of the production cycle.

Straw bales and oat hulls may serve different functions within a commercial house and therefore may be compatible enrichments if provided together. There was no effect on the types of behaviours performed with oat hulls or bales when they were placed near to the alternative enrichment (in the $\mathrm{OH}+\mathrm{B}$ treatment), compared to when they were placed in individual houses $(\mathrm{OH}$ or $\mathrm{B}$ treatments). Both enrichments still continued to attract the same number of birds in single and combined conditions, which suggests there would be no 
impact on straw bale use if oat hulls were provided as a supplementary enrichment. There were also no negative effects on production or any environmental parameters of combining both enrichment types. It is important that enrichments have no negative effect on productivity in order for them to be successfully introduced commercially. Previous nutrition studies have found ground oat hulls to have no negative effect on broiler weight gain and to actually improve feed consumption and conversion efficiency (Hetland and Svihus, 2001; Hetland et al., 2003). There was also no effect of treatment on ammonia levels or litter quality, and no influence on the percentage of pododermatitis recorded. The dry nature of the oat hulls was expected to improve litter quality, and therefore reduce incidences of pododermatitis (Bilgili et al., 2009), however its restriction to rings around the house is likely to have limited its effectiveness in this respect. Although dust levels were not monitored in this study, previous reports of problems with the dustiness of oat hulls have been reported (Meyer et al., 2007), and should be considered in further trials.

\section{Conclusions}

In conclusion, broilers housed with oat hulls as a dustbathing enrichment, both singly and in combination with straw bales, had better gait scores than those in the control treatment with no enrichment. Oat hulls appear to be a more effective enrichment in terms of promoting more foraging and dustbathing than straw bales, however bales were dismantled throughout the trial and the high number of birds sitting around the bales suggests their value as cover for the birds. This trial offers conflicting results to previous research, as we found an increase in activity in the control treatment compared to unenriched areas of the enriched treatments, which we suggest may be due to birds using areas away from enrichments primarily for rest. We measured no effect on the level of use of each enrichment, and no negative effect on performance or environmental measures, when both types of enrichment were provided together, which suggests oat hulls would be suitable as a supplementary enrichment to straw bales. 


\section{Acknowledgments}

This research project was funded by the Department for Employment and Learning in Northern Ireland. The authors also wish to thank Stephen Bell and Moy Park Ltd for allowing access to the farm and for their support and advice throughout the project.

8. References

Bailie, C. L., Ball, M. E. E., and O'Connell, N. E. (2013). Influence of the provision of natural light and straw bales on activity levels and leg health in commercial broiler chickens. Animal, 7(04), 618-626.

Bailie, C. L., and O'Connell, N. E. (2014). The effect of level of straw bale provision on the behaviour and leg health of commercial broiler chickens. Animal, 8(10), 1715-1721.

Baxter, M. and O'Connell, N. E. (2016). Commercial comparison of potential dustbathing substrates for intensively farmed broilers. $67^{\text {th }}$ Annual Meeting of the European Association for Animal Production. Belfast, 2016. The Netherlands: Wageningen Academic Publishers.

Bessei, W. (2006). Welfare of broilers: a review. World's Poultry Science Journal, 62(03), 455-466.

Bilgili, S. F., Hess, J. B., Blake, J. P., Macklin, K. S., Saenmahayak, B., and Sibley, J. L. (2009). Influence of bedding material on footpad dermatitis in broiler chickens. The Journal of Applied Poultry Research, 18(3), 583-589.

Bizeray, D., Estevez, I., Leterrier, C., and Faure, J. M. (2002a). Effects of increasing environmental complexity on the physical activity of broiler chickens. Applied Animal Behaviour Science, 79(1), 27-41.

Bizeray, D., Leterrier, C., Constantin, P., Le Pape, G., and Faure, J. M. (2002b). Typology of activity bouts and effect of fearfulness on behaviour in meat-type chickens. Behavioural processes, 58(1), 45-55. 
Bokkers, E. A., and Koene, P. (2003). Behaviour of fast-and slow growing broilers to 12 weeks of age and the physical consequences. Applied Animal Behaviour Science, 81(1), 59-72.

Campbell, G., and Skillings, J. H. (1985). Nonparametric stepwise multiple comparison procedures. Journal of the American Statistical Association, 80(392), 998-1003.

CIWF, 2017. Good Chicken Award [online]. Available at https://www.compassioninfoodbusiness.com/awards/good-chicken-award/eligibilityand-criteria/ (Accessed 10/08/2017).

Cornetto, T., and Estevez, I. (2001a). Behavior of the domestic fowl in the presence of vertical panels. Poultry Science, 80(10), 1455-1462.

Cornetto, T., and Estevez, I. (2001b). Influence of vertical panels on use of space by domestic fowl. Applied Animal Behaviour Science, 71(2), 141-153.

Danbury, T. C., Weeks, C. A., Chambers, J. P., Waterman-Pearson, A. E., and Kestin, S. C. (2000). Self-selection of the analgesic drug carprofen by lame broiler chickens. The Veterinary Record, 146, 307-311.

Dawson, J. S., and Siegel, P. B. (1967). Behavior patterns of chickens to ten weeks of age. Poultry Science, 46(3), 615-622.

de Jong, I. C., Wolthuis-Fillerup, M., and van Reenen, C. G. (2007). Strength of preference for dustbathing and foraging substrates in laying hens. Applied Animal Behaviour Science, 104(1-2), 24-36.

Dewey, C. E., Cox, B., and Leyenaar, J. (2000). Measuring ammonia concentrations in the barn using the Draeger ${ }^{\mathrm{TM}}$ and pHydrion $^{\mathrm{TM}}$ tests. Swine Health and Production, 8(3), $127-131$

Fraser, D., and Duncan, I. J. (1998). “Pleasures”,'Pains' and Animal Welfare: Toward a Natural History of Affect. Animal Welfare, 7, 383-396.

Garner, J. P., Falcone, C., Wakenell, P., Martin, M., and Mench, J. A. (2002). Reliability and validity of a modified gait scoring system and its use in assessing tibial dyschondroplasia in broilers. British poultry science, 43(3), 355-363. 
Hetland, H., and Svihus, B. (2001). Effect of oat hulls on performance, gut capacity and feed passage time in broiler chickens. British poultry science, 42(3), 354-361.

Hetland, H., Svihus, B., and Krogdahl, Å. (2003). Effects of oat hulls and wood shavings on digestion in broilers and layers fed diets based on whole or ground wheat. British poultry science, 44(2), 275-282.

Jones, R. B., and Waddington, D. (1992). Modification of fear in domestic chicks, Gallus gallus domesticus, via regular handling and early environmental enrichment. Animal Behaviour, 43(6), 1021-1033.

Kells, A., Dawkins, M. S., and Borja, M. C. (2001). The effect of a 'freedom food' enrichment on the behaviour of broilers on commercial farms. Animal Welfare, 10(4), 347-356.

Knowles, T. G., Kestin, S. C., Haslam, S. M., Brown, S. N., Green, L. E., Butterworth, A., Pope, S. J., Pfieffer, D. and Nicol, C. J. (2008). Leg disorders in broiler chickens: prevalence, risk factors and prevention. Plos one, 3(2), e1545.

Krause, E. T., Naguib, M., Trillmich, F., and Schrader, L. (2006). The effects of short term enrichment on learning in chickens from a laying strain (Gallus gallus domesticus). Applied Animal Behaviour Science, 101(3), 318-327.

Lindberg, A. C., and Nicol, C. J. (1997). Dustbathing in modified battery cages: Is sham dustbathing an adequate substitute?. Applied Animal Behaviour Science, 55(1-2), 113128.

Lindqvist, C., Zimmerman, P., and Jensen, P. (2006). A note on contrafreeloading in broilers compared to layer chicks. Applied Animal Behaviour Science, 101(1), 161-166.

McLean, J.A., Savory, C.J., and Sparks N.H.C. (2002). Welfare of male and female broiler chickens in relation to stocking density, as indicated by performance, health and behaviour. Animal Welfare, 11, 55-73.

Mench, J. A., Garner, J.P. and Falcone, C. (2001). Behavioural activity and its effects on leg problems in broiler chickens. Proceedings $6^{\text {th }}$ European Symposium Poultry Welfare, Zollikofen, Switzerland, 1-4 September: 132-135. 
Meyer, D. J., Timms, L., Moody, L., and Burns, R. (2007). Recycling digested manure solids for dairies. In Sixth International Dairy Housing Conference Proceeding, 16-18 June 2007 (Minneapolis, Minnesota)(Electronic Only) (p. 6). American Society of Agricultural and Biological Engineers.

Newberry, R. C. (1995). Environmental enrichment: increasing the biological relevance of captive environments. Applied Animal Behaviour Science, 44(2-4), 229-243.

Newberry, R. C., and Shackleton, D. M. (1997). Use of visual cover by domestic fowl: a Venetian blind effect?. Animal Behaviour, 54(2), 387-395.

Newberry, R. C. (1999). Exploratory behaviour of young domestic fowl. Applied animal behaviour science, 63(4), 311-321.

Nicol, C. J., \& Guilford, T. (1991). Exploratory activity as a measure of motivation in deprived hens. Animal Behaviour, 41(2), 333-341.

Nørgaard-Nielsen, G., Vestergaard, K., and Simonsen, H. B. (1993). Effects of rearing experience and stimulus enrichment on feather damage in laying hens. Applied Animal Behaviour Science, 38(3-4), 345-352.

Osborne, S. R. (1977). The free food (contrafreeloading) phenomenon: A review and analysis. Learning and Behavior, 5(3), 221-235.

Petherick, J. C., and Duncan, I. J. H. (1989). Behaviour of young domestic fowl directed towards different substrates. British Poultry Science, 30(2), 229-238.

Reed, H. J., Wilkins, L. J., Austin, S. D., and Gregory, N. G. (1993). The effect of environmental enrichment during rearing on fear reactions and depopulation trauma in adult caged hens. Applied Animal Behaviour Science, 36(1), 39-46.

Reiter, K. and Bessei, W. (1996). Effect of the distance between feeder and drinker on behaviour and leg disorders of broilers Proceedings of the 30th International Congress of Applied Ethology, Guelph, Canada, 131-132. 
Rutten, M., Leterrier, C., Constantin, P., Reiter, K., and Bessei, W. (2002). Bone development and activity in chickens in response to reduced weight-load on legs. Animal Research, 51(4), 327-336.

Sandusky, C. L., and Heath, J. L. (1988). Effect of age, sex, and barriers in experimental pens on muscle growth. Poultry science, 67(12), 1708-1716.

Shields, S. J., Garner, J. P., and Mench, J. A. (2004). Dustbathing by broiler chickens: a comparison of preference for four different substrates. Applied Animal Behaviour Science, 87(1), 69-82.

Shields, S. J., Garner, J. P., and Mench, J. A. (2005). Effect of sand and wood-shavings bedding on the behavior of broiler chickens. Poultry science, 84(12), 1816-1824.

Thorp, B. H., and Duff, S. R. (1988). Effect of exercise on the vascular pattern in the bone extremities of broiler fowl. Research in Veterinary Science, 45(1), 72-77.

van Liere, D. W., Aggrey, S. E., Brouns, F. M. R., and Wiepkema, P. R. (1991). Oiling behaviour and the effect of lipids on dustbathing behaviour in laying hens Gallus gallus domesticus. Behavioural Processes, 24(1), 71-81.

Vestergaard, K. S., and Sanotra, G. S. (1999). Relationships between leg disorders and changes in the behaviour of broiler chickens. The Veterinary Record, 144(8), 205-209.

Vestergaard, K. S., Skadhauge, E., and Lawson, L. G. (1997). The stress of not being able to perform dustbathing in laying hens. Physiology and behavior, 62(2), 413-419.

Weeks, C. A., Nicol, C. J., Sherwin, C. M., and Kestin, S. C. (1994). Comparison of the behaviour of broiler chickens in indoor and free-range environments. Animal Welfare, 3(3), 179-192.

Weeks, C. A., Danbury, T. D., Davies, H. C., Hunt, P., and Kestin, S. C. (2000). The behaviour of broiler chickens and its modification by lameness. Applied animal behaviour science, 67(1), 111-125. 


\section{Tables and Figures}

Table 1. Ethogram of broiler chicken behaviours used in the present trial, based on Cornetto and Estevez (2001a) and Shields et al. (2005)

\begin{tabular}{|c|c|}
\hline Behaviour & Definition \\
\hline Dustbathing & $\begin{array}{l}\text { Birds were performing classic vertical wing shakes, and/or clearly } \\
\text { covered in substrate and performing side-rubs or prone leg scratches }\end{array}$ \\
\hline Foraging & $\begin{array}{l}\text { Scratching and pecking at the substrate (from a standing or walking } \\
\text { position) }\end{array}$ \\
\hline Sitting inactive & Sitting with no other activity \\
\hline Sitting pecking & Sitting and ground pecking \\
\hline Locomotion & Standing or walking, with no other pecking or scratching activity \\
\hline Sitting preening & Preening, running beak through feathers, while sitting \\
\hline Standing preening & Preening, running beak through feathers, while standing \\
\hline Resting & $\begin{array}{l}\text { Sitting with head under wing, eyes obviously closed, or lying on one } \\
\text { side with a leg and/or wing stretched out }\end{array}$ \\
\hline Other & Any other behaviours \\
\hline
\end{tabular}


Table 2. The effect of enrichment type on the behaviour of broilers in unenriched areas of the house, on health and productivity measures, and on environmental measures

\begin{tabular}{|c|c|c|c|c|c|}
\hline \multirow[b]{3}{*}{ Behaviour in unenriched areas ${ }^{1}(\%$} & \multicolumn{4}{|c|}{ Treatment } & \multirow[b]{2}{*}{$P$ value } \\
\hline & Oat Hulls & Bales & Oat Hulls + Bales & Control & \\
\hline & & & & & \\
\hline Foraging & $0.99(0.00,2.12)$ & $1.03(0.00,2.42)$ & $0.00(0.00,1.84)$ & $0.77(0.00,2.24)$ & ns \\
\hline Sitting Inactive & $54.82(52.81,63.37)^{a}$ & $54.46(49.05,59.27)^{\mathrm{a}}$ & $54.52(45.44,59.04)^{a}$ & $7.22(4.17,11.29)^{b}$ & $<0.001$ \\
\hline Sitting Pecking & $7.57(3.96,10.64)^{a}$ & $8.66(6.82,10.60)^{\mathrm{a}}$ & $6.00(5.01,9.68)^{\mathrm{a}}$ & $0.00(0.00,0.00)^{\mathrm{b}}$ & $<0.001$ \\
\hline Locomotion & $9.04(7.14,10.89)^{b}$ & $12.44(6.19,14.01)^{b}$ & $9.30(3.36,14.10)^{b}$ & $61.48(56.77,67.16)^{\mathrm{a}}$ & $<0.001$ \\
\hline Sitting Preening & $7.09(4.51,9.52)^{\mathrm{ab}}$ & $6.56(4.78,8.42)^{\mathrm{ab}}$ & $9.52(7.13,11.06)^{a}$ & $5.64(4.80,6.31)^{\mathrm{b}}$ & 0.048 \\
\hline Standing Preening & $0.00(0.00,1.20)^{b}$ & $0.84(0.00,1.71)^{b}$ & $0.87(0.52,2.04)^{\mathrm{b}}$ & $7.71(4.20,9.57)^{\mathrm{a}}$ & $<0.001$ \\
\hline Resting & $6.68(5.23,13.44)$ & $12.60(4.55,16.22)$ & $15.47(8.05,23.48)$ & $10.98(5.11,16.16)$ & ns \\
\hline \multicolumn{6}{|l|}{ Health and performance ${ }^{2}$ : } \\
\hline Pododermatitis (\%) & $33.64 \pm 10.45$ & $35.18 \pm 10.70$ & $29.19 \pm 11.84$ & $33.06 \pm 8.43$ & ns \\
\hline Average slaughter weight $(\mathrm{g})$ & $2.10 \pm 0.047$ & $2.12 \pm 0.05$ & $2.17 \pm 0.05$ & $2.19 \pm 0.39$ & ns \\
\hline Mortality (\%) & $1.55 \pm 0.09$ & $1.08 \pm 0.12$ & $1.04 \pm 0.16$ & $1.32 \pm 0.15$ & 0.003 \\
\hline Culls (\%) & $0.63 \pm 0.17$ & $0.41 \pm 0.09$ & $0.53 \pm 0.14$ & $0.34 \pm 0.043$ & ns \\
\hline Downgrades (\%) & $0.71 \pm 0.17$ & $0.70 \pm 0.07$ & $0.70 \pm 0.13$ & $0.61 \pm 0.075$ & ns \\
\hline \multicolumn{6}{|l|}{ Environmental measures ${ }^{2}$ : } \\
\hline Litter moisture (\%) & $26.08 \pm 2.92$ & $28.73 \pm 2.22$ & $26.46 \pm 2.10$ & $28.06 \pm 1.75$ & ns \\
\hline Ammonia (ppm) & $6.46 \pm 2.35$ & $7.50 \pm 3.24$ & $6.35 \pm 3.05$ & $7.60 \pm 3.15$ & ns \\
\hline
\end{tabular}

${ }^{1}$ Median values (95\% confidence intervals); ${ }^{2}$ Mean values \pm standard error.

Different letters along horizontal rows indicate significance in pairwise comparisons from Kruskall-Wallis rank test. 
Table 3. The behaviour of broilers using enrichments in the single treatment (either $\mathrm{OH}$ or $\mathrm{B}$ ), compared to their counterpart in the combined treatment $(\mathrm{OH}+\mathrm{B})$

\begin{tabular}{|c|c|c|c|c|c|c|}
\hline \multirow[b]{2}{*}{ Behaviour (\%): } & \multicolumn{3}{|c|}{ Oat Hulls } & \multicolumn{3}{|c|}{ Bales } \\
\hline & $\mathrm{OH}$ & $\mathrm{OH}+\mathrm{B}$ & $P$ value & $\mathrm{B}$ & $\mathrm{OH}+\mathrm{B}$ & $P$ value \\
\hline Dustbathing & $12.67(6.73,18.60)$ & $15.41(9.32,21.50)$ & 0.346 & $0.058(-.065,0.18)$ & $0.60(-.68,1.89)$ & 0.391 \\
\hline Foraging & $28.39(18.73,38.05)$ & $29.15(21.54,36.76)$ & 0.876 & $4.62(3.07,8.20)^{1}$ & $5.67(2.83,8.20)^{1}$ & 0.528 \\
\hline Sitting Inactive & $17.94(12.43,23.46)$ & $16.50(12.56,20.45)$ & 0.795 & $49.87(41.67,58.08)$ & $49.03(39.23,58.83)$ & 0.818 \\
\hline Sitting Pecking & $23.34(19.0,28.65)^{1}$ & $22.01(17.88,27.05)^{1}$ & 0.290 & $10.21(6.92,13.50)$ & $8.88(6.28,11.49)$ & 0.680 \\
\hline Locomotion & $8.38(5.25,11.51)$ & $9.81(7.42,12.20)$ & 0.176 & $4.62(3.07,6.76)^{1}$ & $5.67(3.83,6.76)^{1}$ & 0.506 \\
\hline Preening & $3.78(2.50,5.06)$ & $2.74(1.28,4.20)$ & 0.279 & $7.76(4.77,10.75)$ & $6.74(4.62,8.86)$ & 0.452 \\
\hline Resting & $1.74(0.81,3.14)^{1}$ & $1.97(0.96,3.50)^{1}$ & 0.445 & $4.98(3.12,7.69)^{1}$ & $3.93(2.40,6.16)^{1}$ & 0.294 \\
\hline
\end{tabular}

${ }^{1}$ Means and confidence intervals have been backtransformed to their original scale 
Table 4. The effects of enrichment type and age on behaviours performed in oat hulls and around straw bales

\begin{tabular}{|c|c|c|c|c|c|c|c|c|}
\hline \multirow[b]{2}{*}{ Behaviour (\%): } & \multicolumn{2}{|c|}{ Mean \pm SE } & \multicolumn{2}{|c|}{ Enrichment } & \multicolumn{2}{|c|}{ Age } & \multicolumn{2}{|c|}{ Age Enrichment } \\
\hline & Oat Hulls & Bales & $F(d f)$ & $P$ value & $F(d f)$ & $P$ value & $F(d f)$ & $P$ value \\
\hline Dustbathing & $14.04 \pm 1.98$ & $0.33 \pm 0.30$ & $10.98(1,3)$ & 0.045 & $6.373(3,9)$ & 0.013 & $8.004(3,9)$ & 0.007 \\
\hline Foraging & $28.77 \pm 2.84$ & $6.35 \pm 0.84$ & $21.66(1,3)$ & 0.019 & $11.17(3,9)$ & 0.002 & $12.09(3,9)$ & 0.002 \\
\hline Sitting Inactive & $17.22 \pm 1.57$ & $49.46 \pm 2.95$ & $37.84(1,3)$ & 0.009 & $1.24(3,9)$ & ns & $1.58(3,9)$ & ns \\
\hline Sitting Pecking & $24.25 \pm 1.56$ & $9.55 \pm 0.97$ & $14.97(1,3)$ & 0.031 & $1.45(3,9)$ & ns & $1.97(3,9)$ & ns \\
\hline Locomotion & $9.10 \pm 0.92$ & $19.95 \pm 2.83$ & $9.89(1,3)$ & $0.051^{\dagger}$ & $0.56(3,9)$ & ns & $3.88(3,9)$ & $0.050^{\dagger}$ \\
\hline Preening & $3.26 \pm 0.46$ & $7.25 \pm 0.85$ & $11.93(1,3)$ & 0.041 & $4.09(3,9)$ & 0.044 & $0.58(3,9)$ & ns \\
\hline Resting & $3.14 \pm 0.89$ & $5.83 \pm 0.79$ & $3.75(1,3)$ & ns & $2.85(3,9)$ & $0.097^{\dagger}$ & $3.01(3,9)$ & $0.087^{\dagger}$ \\
\hline Other & $0.22 \pm 0.078$ & $1.31 \pm 0.20$ & $12.34(1,3)$ & 0.039 & $0.63(3,9)$ & ns & $0.30(3,9)$ & ns \\
\hline
\end{tabular}

${ }^{\dagger} P<0.1$ 
Table 5. Distribution of the frequencies of gait score ${ }^{1}(\%)$

Week 3

\begin{tabular}{|c|c|c|c|c|c|c|}
\hline \multirow[b]{2}{*}{ Treatment } & \\
\hline & GSO & GS1 & GS2 & GS3 & GS4 & GS5 \\
\hline Rings & 69.4 & 26.3 & 4.4 & 0 & 0 & 0 \\
\hline Bales & 69.4 & 28.8 & 1.9 & 0 & 0 & 0 \\
\hline Rings + Bales & 66.3 & 33.1 & 0.6 & 0 & 0 & 0 \\
\hline \multirow[t]{3}{*}{ Control } & 65.0 & 33.8 & 1.3 & 0 & 0 & 0 \\
\hline & \multicolumn{6}{|c|}{ Week 4} \\
\hline & GSO & GS1 & GS2 & GS3 & GS4 & GS5 \\
\hline Rings & 13.1 & 66.3 & 20.0 & 0.6 & 0 & 0 \\
\hline Bales & 13.1 & 61.9 & 17.5 & 1.9 & 0 & 0 \\
\hline Rings + Bales & 16.3 & 57.5 & 26.3 & 0 & 0 & 0 \\
\hline \multirow[t]{3}{*}{ Control } & 8.8 & 69.4 & 20.0 & 1.9 & 0 & 0 \\
\hline & \multicolumn{6}{|c|}{ Week 5} \\
\hline & GSO & GS1 & GS2 & GS3 & GS4 & GS5 \\
\hline Rings & 2.5 & 52.5 & 41.3 & 1.9 & 2.5 & 0 \\
\hline Bales & 1.3 & 52.5 & 41.3 & 5.0 & 0 & 0 \\
\hline Rings + Bales & 3.1 & 59.4 & 33.1 & 4.4 & 0 & 0 \\
\hline \multirow[t]{3}{*}{ Control } & 0.6 & 56.3 & 39.4 & 3.8 & 0 & 0 \\
\hline & \multicolumn{6}{|c|}{ Week 6} \\
\hline & GSO & GS1 & GS2 & GS3 & GS4 & GS5 \\
\hline Rings & 0 & 43.1 & 45.6 & 8.8 & 1.3 & 1.3 \\
\hline Bales & 0 & 33.1 & 61.9 & 5.0 & 0 & 0 \\
\hline Rings + Bales & 0 & 43.8 & 44.4 & 11.3 & 0.6 & 0 \\
\hline Control & 0 & 26.9 & 62.5 & 10.0 & 0.6 & 0 \\
\hline
\end{tabular}

${ }^{1} \mathrm{GSO}=$ gait score $0, \mathrm{GS} 1$ = gait score 1 etc . 


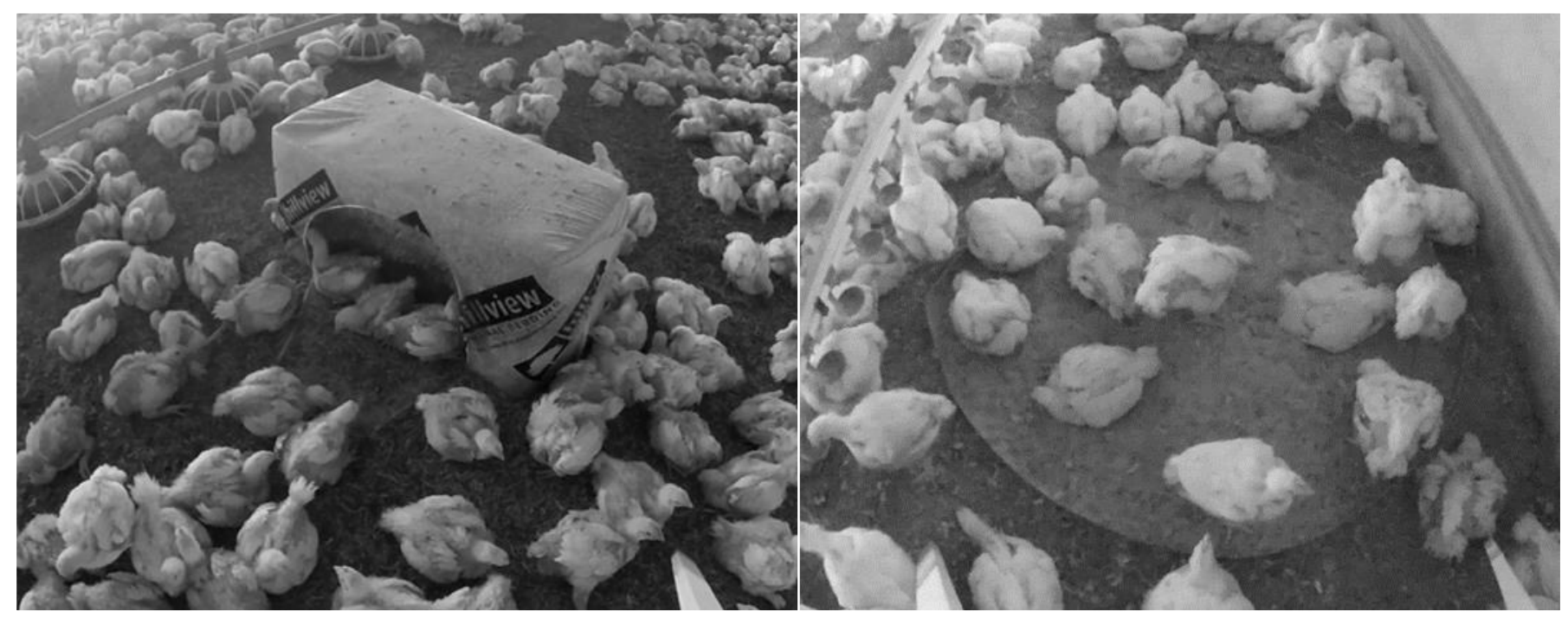

Figure 1. Photograph of the enrichments used throughout the trial: plastic-wrapped, short cut straw bales (left) and steel rings of ground oat hulls (right). 


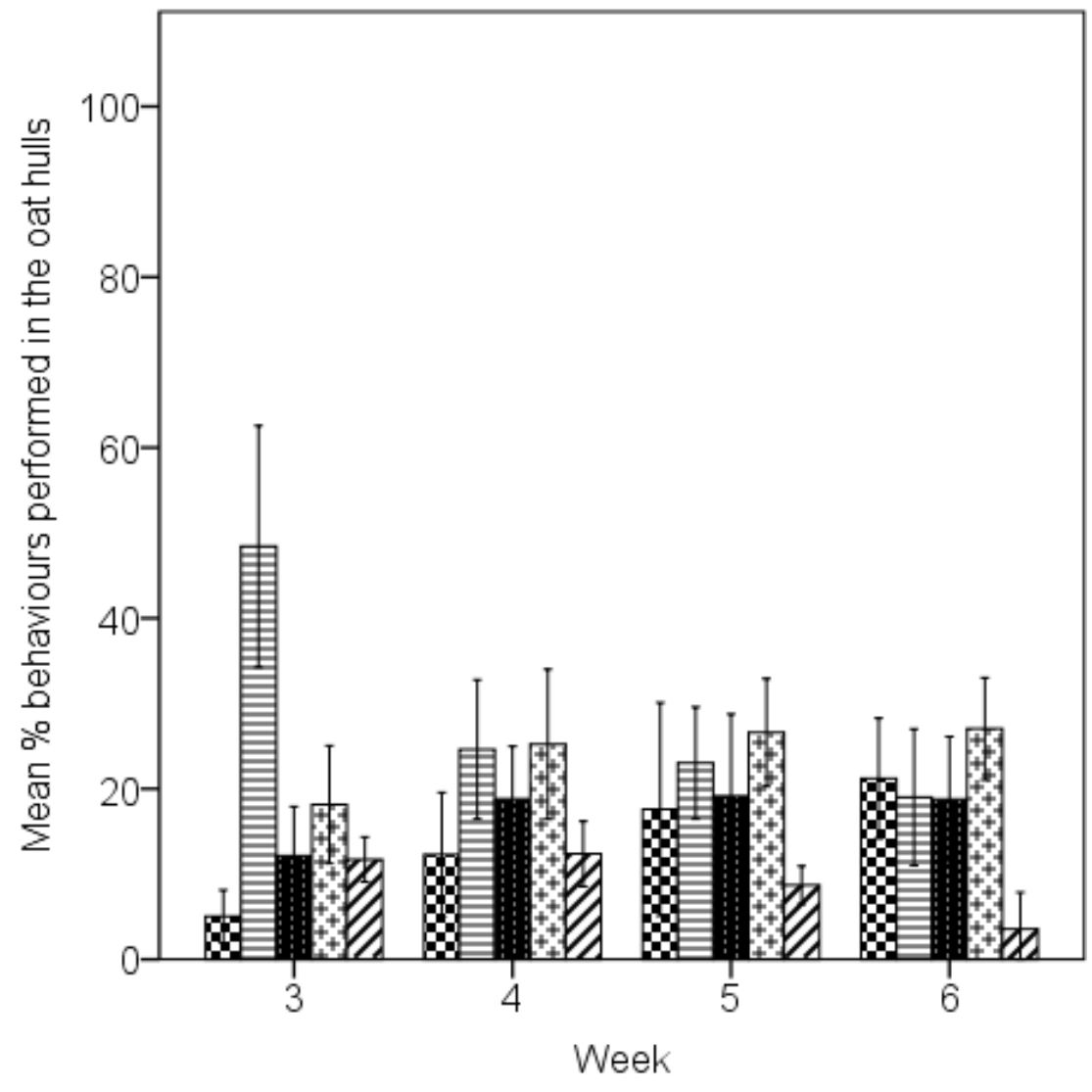

Error Bars: $95 \% \mathrm{Cl}$

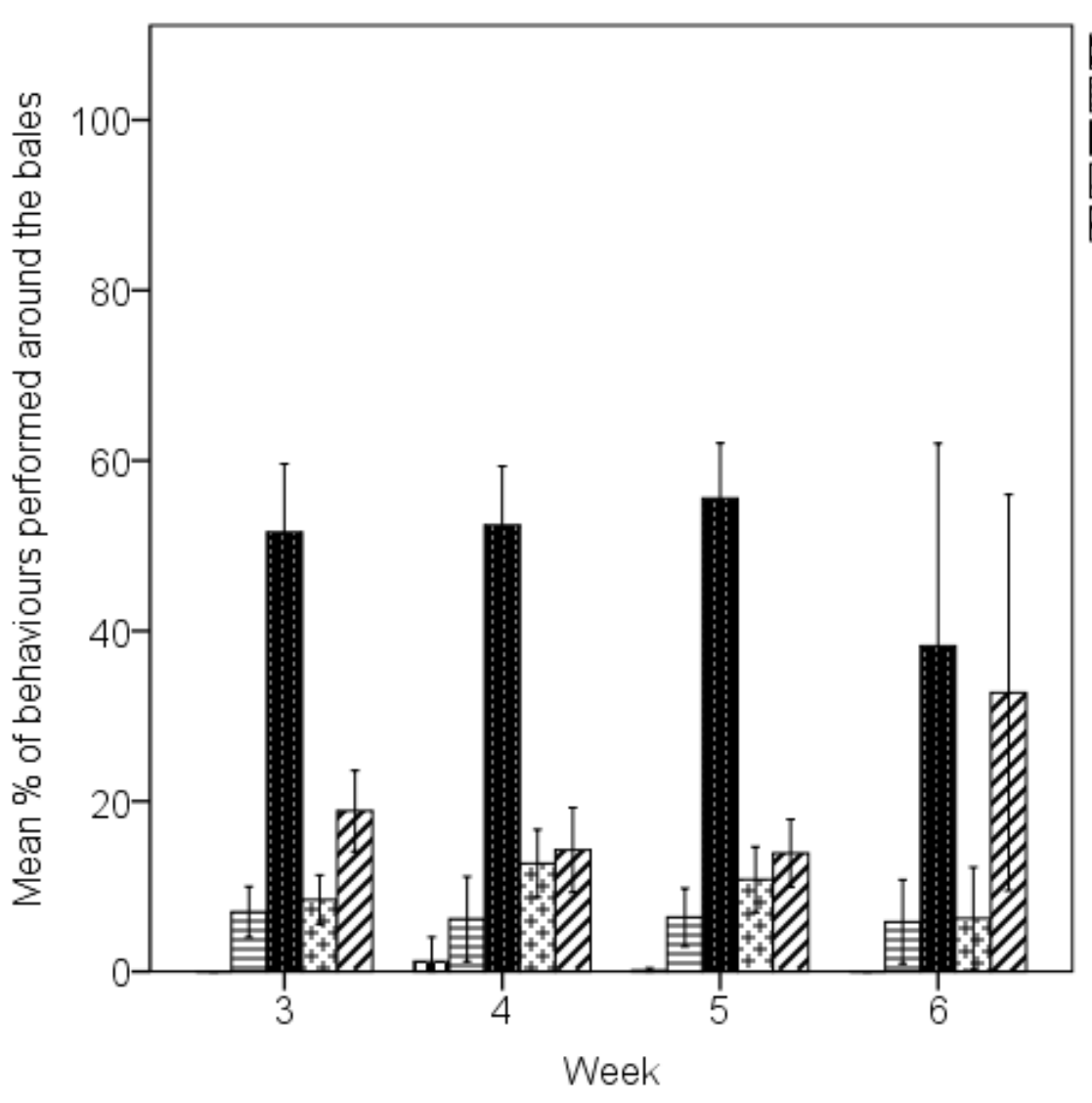

Error Bars: $95 \% \mathrm{Cl}$
BDustbathing

具Foraging

Sitting Inactive + + Sitting Pecking

ZLocomotion

Figure 2. The effect of age on the mean \% of behaviours performed in the oat hulls (left) and around the straw bales (right). 